\title{
I. PERSPECTIVAS
}

\section{A Literatura Brasileira em 1972}

Será possível a um contemporâneo dizer o que está acontecendo de realmente importante na literatura de seu país? Muitas vezes o que há de importante não aparece no momento em que ocorre; está nos níveis escondidos, nas correntes subterrâneas, nos gritos sem eco. Permitam-me, pois, falar apenas sobre o que estou vendo na literatura atual do Brasil, colocando esta palestra sob a égide de um aforismo de Murilo Mendes: "Poucos homens atingem sua época".

Vejo algumas coisas que animam, outras que inquietam, outras que apenas aguçam o desejo de compreender. Parece-me, por exemplo, que há uma falta alarmante de obras de alto nível nos gêneros tradicionais, entre as publicações recentes. Mas como há uma grande confusão entre estes gêneros, talvez isto signifique a queda das barreiras entre eles, para deixar surgirem as obras mais livres do futuro, o que seria saudável. É visível a dessacralização da literatura, com os escritores perdendo cada vez mais a aura que os cercava, e isto leva a perguntar se não há mais escritores realmente grandes, ou se os escritores não mais parecem grandes porque são encarados sem a reverência tradicional.

Olhando por alto a produção literária, há um fato que talvez em parte explique e justifique isto: a consolidação da média, sem a qual não há produção regular de boa qualidade e cuja falta Mário de Andrade lamentava há uns quarenta anos. Hoje há um maior número de bons escritores do que em qualquer outra época, mas nenhuma grande revelação decisiva depois dos livros de João Cabral de Melo Neto e Guimarães Rosa, que estreiaram entre 1942 e 1946, atingindo a maturidade nos anos 50.

Em compensação (se for compensação) há um notório refinamento e progresso na crítica literária em geral. Os próprios escritores criativos vãose tornando cada vez mais críticos, e às vezes escrevem poemas e romances como quem apresenta uma demonstração prática das suas idéias. Daí um fato novo dos últimos anos: não é mais possível entender bem a maioria dos poetas significativos de vanguarda sem primeiro estudar os seus ensaios 
críticos. Antes, era freqüente vermos a mentalidade e o estilo dos gêneros criativos contaminarem a crítica; agora, parece que a mentalidade e o estilo da crítica estão contaminando a fíç̧ão e a poesia.

Mas é também considerável o progresso da crítica literária propriamente dita; e este é no Brasil um fato singular dos nossos dias.

É verdade que nem tudo foi lucro deste lado. Os hábitos modernos da notícia curta e da resenha mataram praticamente a velha instituição do rodapé semanal, herdeiro do folhetim, que vinha do século passado e chegou a ter no Brasil, entre 1930 e 1950, grande importância na orientação do gosto e no movimento da vida literária. Hoje, o rodapé acabou, como disposição gráfica, isto é, a composição no quarto inferior da página de jornal. Quanto ao espírito, resta um ou outro crítico de rodapé com o seu artigo de seis laudas, devendo-se mencionar Wilson Martins no Suplemento Literário d 'O Estado de São Paulo. Talvez esta mudança tenha privado o leitor comum de um tipo bem elaborado de discussão crítica, que não foi compensada pelo grande desenvolvimento da notícia rápida e da mera informação publicitária.

Mas de modo geral a crítica subiu de nível e se diversificou, desde a investigação erudita até o artigo dos suplementos literários, passando pelo estudo analítico das revistas e o livro de ensaios.

No Brasil, só agora se firmou um bom padrão de investigação erudita, que nos países adiantados era moeda corrente havia tanto tempo, e entre nós sempre foi exceção. Mesmo porque, o estudo e o ensino da literatura só chegaram ao nível universitário nos anos de 30 . Hoje, já se vai acentuando o rigor das Universidades no preparo das teses, e já vai aparecendo inclusive a indispensável base financeira para este tipo de trabalho, notadamente o apoio dado sob forma de bolsas e subvenções pela Fundação de Amparo à Pesquisa do Estado de São Paulo. Interessante é o fato deste esforço de investigação erudita se voltar frequientemente para a literatura moderna, como o que vem sendo feito por bolsistas desta Fundação e por um certo número de pesquisadores ligados ao Instituto de Estudos Brasileiros da Universidade de São Paulo.

Além da pesquisa, desenvolve-se também a analise literária de intenção sistemática, inspirada freqüentemente pelos métodos estruturais, como no grupo da Universidade do Rio de Janeiro e o que se exprime em geral pela revista Vozes. Outros, como alguns jovens professores da Universidade de São Paulo, procuram evitar o que há de mecânico em tais métodos, concebendo os estudos de estilo e estrutura num contexto mais largo, que não perde de vista as implicações culturais. Com certeza interessará a este público, voltado para a leitura de autores hispanoamericanos, saber que recentemente um desses jovens professores apresentou sobre Cortázar uma tese de grande importância, pelo refinamento e a penetração.

Além da critica de tipo universitário, o ensaio propriamente dito também está passando por uma fase de boa qualidade, cujo início podemos 
datar da estréia de alguns críticos atualmente na casa dos trinta anos, como Roberto Schwarz. Aliás, o espírito ensaístico penetra com frequência em muitas teses universitárias, dando-lhes flexibilidade e urbanidade. Este tipo de escritos é freqüentemente nutrido de pontos de vista filosóficos, inclusive a influência de marxistas como Lukács e de pensadores inspirados no marxismo, como Theodor Adorno e Walter Banjamin. Eu mencionaria o livro recente de José Guilherme Merquior, $A$ astúcia da mímese, como exemplo da convergência destas orientações com outras, notadamente a moderna reflexão antropológica.

Não sei se seria injusto dizer que alguns dos poetas mais interessantes dos últimos anos são mais válidos pela exposição crítica e polêmica das suas idéias do que pela sua produção poética. Mas pensando agora nesta, digamos que eles se formaram sobretudo a partir das discussões sobre a renovação dos meios poéticos, tendo como pontos de referência, no decênio de 1950, o Suplemento Dominical do Jornal do Brasil , do Rio de Janeiro, podendo-se juntar logo a seguir publicações periódicas como Invenção e Praxis, de São Paulo, e Tendência de Belo Horizonte. Destas discussōes e das experiências poéticas conexas, sairam sucessivamente o Concretismo, representado pelo grupo de Noigandres, revista antológica, o mesmo que publicou depois Invenção; o Neo-concretismo, do Rio, ligado ao grupo do Jornal do Brasil; a Poesia-Praxis, ligada ao grupo da revista Praxis, e mais alguns poetas e tendências.

Como poetas, os membros destes grupos têm muitas diferenças uns com os outros, e mais ainda os grupos entre si. Mas há alguns traços comuns, isolados ou combinados de vário modo, como por exemplo: importância atribuida à distribuição gráfica dos signos; valor do espaço da página; uso intensivo da elipse e do subentendido; contestação do verso como condição de poesia; desconfiança da figuração analógica. Forçando bastante, seria possível tentar caracterizar estas correntes, por vezes inimigas entre si, pelo seguinte resumo: supressão dos nexos sintáticos e conseqüente descontinuidade do discurso; substituição da ordem temporal, linear, por uma ordem espacio-temporal, não linear; substituição da metáfora pela paronomásia.

Estas características representam o elemento inovador e experimental no panorama poético, e acabaram em muitos casos penetrando na própria poesia de cunho mais tradicional. Contribuiram, sobretudo, para levar às últimas consequências certas tendências que vinham do Modernismo dos anos 20 , como a estética do fragmento, as intenções anti-líricas e um certo gosto pela desarticulação do poema. Com isto, instauraram um ar de jogo combinatório, de experiência calculada e de projeto mental, que contrastava com a expressão dominante no decênio de 50 , a da chamada "geração de 45", formada por poetas inclinados ao mistério, ao sentimentalismo, a um certo patético, embora entre eles se inclua um completamente diferente, João Cabral de Melo Neto, precursor da vanguarda atual. 
Como vimos, os poetas mais marcantes dessa poesia topológica, paronomástica, anti-lírica, são igualmente críticos e nos últimos anos têm feito mais crítica do que poesia. Haroldo de Campos, seu irmão Augusto e Décio Pignatari representam o núcleo do movimento concretista, que levou ao máximo as tendências indicadas acima, enquanto Mário Chamie, inspirador e principal teórico do grupo Praxis, tentou de certo modo preservar a estrutura do poema, além de manter um forte lastro de realidade. As suas experiências são interessantes como tentativa de manter a tradição do Modernismo sem renunciar ao espírito de vanguarda; e neste sentido é ainda mais conservador o neo-concretista Ferreira Gullar, voltado para a expressão política.

Os concretistas ortodoxos, todavia, na medida em que desejam abolir o verso e o tempo linear, podem acabar saindo fora da literatura, em busca de novas formas de arte. Com efeito, a desconfiança em relação ao verso acaba gerando uma desconfiança em relação à própria palavra,e levando a adotar signos não-verbais, como faz Décio Pignatari. Por este lado, ele representa a linha de maior coerência de um movimento que luta contra qualquer vestígio discursivo, rejeita a imagem analógica e confia na relação topológica da palavra, isto é, no sentido que decorre da sua disposição no espaço branco da página, - que para eles, aliás, pode ser azul, vermelho ou preto.

Desde Mallarmé, sabemos que a folha branca é o escolho, o risco, o possível mergulho no nada. Estes poetas se aventuram perigosamente em semelhante navegação, que pode ser guiada por uma estrela, mas pode também levar ao isolamento absoluto, isto é, o ponto zero da comunicação, e daí ao fracasso completo, - como se vê nas alternativas do verso famoso que abre o volume das Poesias, de Mallarmé:

\section{Solitude, récif, étoile.}

Estas tendências, seguidas por poetas que são quase todos também críticos, são cheias de interesse e de ânimo renovador; mas podem comprometer a poesia e, implicitamente, a própria concepção da literatura. Lendo-os, sentimos às vezes como pode ficar tênue, quase impalpável, a fronteira entre poesia e piada, trocadilho, jogo gratuito, associação livre, charada, caricatura, propaganda, representão visual. Mas de qualquer modo, esta poesia de vanguarda representa de maneira viva o passeio pelo fio da navalha, que está sendo em nosso tempo o destino da arte e da literatura, envolvidas no turbilhão da mudança rápida de práticas e valores. E é claro que as suas experiências são mais úteis do que o ato de refazer elegias de Rilke ou sonetos de Fernando Pessoa.

Os poetas mais novos, que estão começando ou se desenvolvendo nos últimos anos, adotam ou não adotam essas práticas e teorias de vanguarda. No segundo caso estão os que continuam a tradição modernista, mais ou menos alteracia pela invasão lírica da geração de 45 e pela própria 
vanguarda dos anos 50 e 60 . Mas sem grande relevo. Também não me parecem relevantes os que têm procurado desenvolver as atitudes de vanguarda, entre os quais podemos mencionar os adeptos do chamado "poema-processo". Na verdade, eles apenas radicalizaram e deram exclusividade à proposição de Pignatari, rejeitando definitivamente a palavra para adotar uma poesia feita apenas com signos visuais. Eles são o termo de uma longa aventura começada há vinte anos pelos então jovens concretistas, fascinados pelos ideogramas chineses, em função dos quais Ezra Pound quis dar um novo sentido à expressão poética.

Resumindo, temos, atualmente lado a lado poetas de vanguarda, criadores e seguidores; poetas que continuam o que foi vanguarda nos anos 20 e 30 ; poetas da geração de 45 e seus seguidores; e, muito curiosamente, alguns grandes modernistas ainda vivos e atuantes.

Com efeito, alguns dos poetas em atividade no Brasil vieram dos anos de 20 e amadureceram nos 30 . Inclusive o caso de Cassiano Ricardo, que tem quase 80 anos, e não apenas se renovou duas vezes ao contacto das novas correntes, mas continua incorporando à sua poesia e à sua ativa reflexão crítica alguns dos desenvolvimentos mais recentes. Foi também o caso espantoso de Manuel Bandeira, morto em 1968 com mais de 80 anos, e que quase até o fim foi capaz de usar experiências de vanguarda e de criar, com uma vitalidade rara em qualquer literatura.

Esta longevidade criadora aparece em dois poetas que, embora tenham 70 anos, são personalidades vivas e atuantes, pela capacidade de assimilar as inovações da vanguarda e pela capacidade mais preciosa de criar as suas próprias inovações: Carlos Drummond de Andrade e Murilo Mendes,- que formam a tríade dos maiores poetas brasileiros vivos com João Cabral de Melo Neto, este, na casa dos 50 anos e podendo por muitos aspectos ser considerado discípulo de ambos.

Eu quiz ressaltar esta vitalidade mental porque ela transformou aqueles poetas em parte viva do que está acontecendo; em figuras características de uma época tumultuosa onde tudo passa depressa e pareceria não haver lugar para os velhos:

That is no country for old men...

Há portanto na poesia uma simultaneidade de tendências e de gerações que parece mistura de momentos diversos do tempo; outras vezes, parece falta de capacidade para criar um novo estilo que predomine. Da mesma maneira por que hoje não há padrões regulares na moda, nem nas convenções, assim também na literatura florescem lado a lado as manifestações mais díspares. $\mathrm{E}$ parece forçoso reconhecer que a verdadeira eminência ainda está com alguns mais velhos, ou simplesmente velhos, que citei intencionalmente por causa disto.

$\mathrm{Na}$ fiç̧ão, nota-se que o embate de tendências é menos acentuado e as inovações, ou menos ousadas, ou menos seguidas. 
$\mathrm{Na}$ poesia de vánguarda, o traço básico foi a ruptura com o elemento discursivo e o lirismo, acompanhada no plano da fatura pela descontinuidade sintática, a sonoridade paronomástica e uma certa espacialização $\mathrm{da}$ estrutura. $\mathrm{Na}$ ficção, foi o intuito de romper com o elemento mimético, apresentado conforme uma lógica realista. Ruptura imperfeita, menos radical que a da poesia e que não tem favorecido na produção mais recentes resultados satisfatórios.

O grande impacto renovador de Clarice Lispector nos anos 40, e o de Guimarães Rosa nos anos 50, parecem ter desnorteado um pouco a fíç̧ão brasileira. Imitá-los, seria difícil, porque apresentam fórmulas demasiado pessoais, sem a racionalização teórica que permite transmiti-las, como as que serviram de base à difusão das inovações poéticas. Além disso, tanto um quanto outro se caracterizaram por desromancizar o romance, puxando-o da prosa para a poesia, do enredo para a sugestão, da coerência temporal para a confusão do tempo. $\mathrm{E}$ isto tudo era mais ou menos difícil de incorporar a um gênero que, ao contrário da poesia, é objeto de uma demanda relativamente grande por parte do público, o que obriga a manter uma certa comunicabilidade.

Por outro lado, era igualmente difícil continuar escrevendo como se aqueles dois grandes escritores não tivessem existido, porque eles abalaram padrões anteriores: os do romance de análise, que Clarice Lispector dissolveu no caleidoscópio das impressões; ou os do romance regional, que Guimarães Rosa despojou das suas duas cômodas muletas, o pitoresco e o realismo. Sem contar que ambos abalaram e questionaram a linguagem da ficção.

Talvez por causa disto, os romancistas mais valiosos de hoje são os que se formaram antes ou à margem da neblina insinuante de Lispector ou do furacão de Rosa. Do mesmo modo, nos anos 30 ficaram alheios às tendências renovadoras e às polêmicas do Modernismo um Graciliano Ramos ou um Ciro dos Anjos.

Em geral, os romancistas nos quais estou pensando começaram a publicar ou se firmaram pela altura de 1950, dentro de uma técnica moderadamente renovadora, que nalguns deles se veio tornando mais experimental com o tempo. Este é o caso de Waldomiro Autran Dourado e sobretudo Osman Lins, para citar apenas dois num conjunto de bons escritores, que deram ao nosso romance uma regularidade de produção nunca vista antes. Mas, é forçoso reconhecer, sem vôos muito altos de talento criador.

Um modo de modernizar a ficção tem sido, ultimamente, apelar para os elementos fantásticos, o insólito, o irreal. As vezes, no contexto de obras que de outro modo seriam banais, e deste modo ganham certo encanto, como o best-seller $O$ coronel e o lobisomem, de José Cândido de Carvalho, publicado há uns dez anos. A propósito, quero mencionar que obras mais originais, embora menos pitorescas, ficaram na sombra porque exploravam este elemento quando ele ainda não estava em moda. E o caso do livro de 
contos $O$ ex-mágico, de Murilo Rubião, que fazia um uso extremamente moderno e avançado do absurdo numa época dominada pela ficção mimética e realista. Quando foi reeditado em $1967 \mathrm{sob}$ o nome de $O s$ dragões e outros contos, pudemos perceber que este discreto cultor do insólito era, guardadas as proporções, um precursor de autores tão avançados quanto Julio Cortázar.

Aliás, o conto está passando por uma boa fase, - talvez porque permita estabelecer, mais facilmente que o romance, ligações com a crônica, a notícia, a anedota, tão gratos ao leitor de hoje. Ao lado de certos traços de super-real, há também nele uma espécie de novo realismo, baseado sobretudo nas alterações da técnica narrativa. E por exemplo o caso de certos contos exclusivamente dialogados de Luis Vilela. Ou de outros feitos em torno de uma ação vivida, como alguns de Rubens Fonseca, onde o narrador na primeira pessoa não tem qualquer afastamento temporal, mas parece estar na própria duração do acontecimento.

Em alguns contistas recentes nota-se a influência mal aproveitada de Clarice Lispector, que além de romances escreveu excelentes contos. E é preciso lembrar os nomes de escritores já consagrados de sua geração, que continuam escrevendo com força criadora, como Dalton Trevisan e Lígia Fagundes Teles, esta, também romancista de qualidade.

Notemos, pois, que enquanto na poesia de vanguarda o afastamento da mimese se deu por um reforço da racionalidade na construção, para elaborar objetos autônomos que toman o lugar dos objetos reais, na ficção esse afastamento se tem dado num duplo sentido: de um lado, uma certa busca anti-racional de elementos insólitos; de outro, uma espécie de reforço da mimese, pela tentativa de suprimir a mediação do narrador.

Nesta mistura de tendências e estilos na ficção e na poesia, interessa procurar as linhas mais originais e os fatos literários mais significativos. Neste sentido, seria exagerado dizer que as tendências de vanguarda predominam, pois elas apenas ocorrem; nos casos mais favoráveis, vão influenciando lentamente os hábitos expressivos tradicionais. Mas de qualquer modo elas representam uma orientação oposta ao que predominou até aqui na própria concepção de literatura, pois não estão mais interessadas na transposição do mundo, e sim em criar pequenos mundos autônomos, que podem lembrar mais ou menos a realidade do mundo que conhecemos, mas não tiram disto o seu significado principal. Certos poemas concretos parecem desprender-se do mundo referencial como um balão que cortou as amarras. Certos romances e contos, embora necessariamente mais ligados a este mundo pelo seu carater discursivo, dissolvem-no através da dispersão dos fragmentos ou da imprecisão do ponto de vista. Talvez estejam buscando aquele alheiamento das forças do mundo que sempre existiu no universo combinatório da música, e em nosso tempo penetrou nas artes plásticas. Mas como realizar isto nos domínios da palavra, que é feita para significar, e que mesmo quando desenvolve ao máximo a função poética, conserva sempre alguma coisa das funções 
comunicativas? As tendências radicais da vanguarda literária parecem lamentar esta sua natureza, e gostariam talvez de modular a palavra como se modulam os sons, ou justapô-lasicomo se justapõem as cores. Daí, como já vimos, muitos se envergonharem da palavra e preferirem disfarçá-la de maneira a fazê-la parecer outra coisa. Talvez por causa disto é que a vida literária vem sendo privada cada vez mais de talentos, pois um grande número de jovens que até há pouco fariam poemas e contos, preferem agora fazer filmes e canções, porque nestas artes a palavra ganha alguma coisa dos outros meios a que está associada.

Estas considerações levam a pensar que a natureza discursiva da palavra está se sentindo por assim dizer constrangida pelo exagero do seu emprego não-referencial, sobretudo pela desarticulação da sintaxe causada pelas tendências de vanguarda desde os anos 20 . E que, em consequência, na medida em que é empurrada para fora da poesia e mesmo do romance, esta vocação referencial volta sob outras formas, para satisfazer a uma necessidade profunda da nossa sensibilidade e da nossa inteligência.

Talvez seja este um dos motivos responsáveis por um traço característico da literatura brasileira atual: a importância crescente dos livros de autobiografia, gênero que sempre foi raro no Brasil, apesar de algumas exceções famosas. A partir de 1933 abriu-se uma fase nova, graças ao sucesso extraordinário das Memórias de Humberto de Campos, sinceras e medíocres. Mais tarde o gênero iria ganhando fisionomia cada vez mais literária, desprendendo-se lentamente do documentário para se tornar uma construção de estilo, como ocorre em Infância, de Graciliano Ramos, de 1945, e na primeira parte de Um homem sem profissāo, de Oswald de Andrade, de 1954. Em tais livros, os fatos narrados na primeira pessoa correspondem sem dúvida à biografia de um homem; mas tratados de tal modo que se lêem também como obras de ficção. Os valores antes procurados no romance, parece que agora estão sendo fornecidos cada vez mais por livros deste tipo, de que a literatura recente oferece bons exemplos. Citemos No tempo da flor, de Augusto Meyer, de 1966, que fora precedido em 1945 por Segredo da infância; citemos mais dois nos quais este gênero atinge a mais alta categoria: $A$ idade do serrote, de Murilo Mendes, de 1970, e Baú de ossos, de Pedro Nava, aparecido agora.

Estes dois últimos livros me parecem representar aquela visão ao mesmo tempo poética e realista que os livros de ficção estão banindo, pelo medo de cederem a uma visão mimética reprovada pelos cânones da vanguarda. Baú de ossos, aliás, é singular, por constituir uma estréia literária aos 70 anos e situar o gênero autobiográfico nas alturas raras da verdadeira criação. Não tenho dúvida em dizer que este livro me parece o mais importante dentre os publicados em 1972.

Poderiamos considerar como fato semelhante no domínio da poesia a ocorrência de certas obras de definição difícil, que podem funcionar como funcionavam os gêneros poéticos; que podem mesmo constituir manifestações da melhor poesia. Eles nos interessam aqui sobretudo como 
sintoma de um certo mecanismo de defesa, por meio do qual a poesia também parece querer preservar os seus elementos discursivos e o seu direito a uma sintaxe regular.

Eu mencionaria o curioso Peripécia de Gerardo, de Gerardo Melo Mourão, publicado em 1972, praticamente continuação de outro do mesmo autor, O país dos Mourōes, de 1964. São longos poemas em verso livre de ritmo prosaico, e parecem mais uma variação autobiográfica misturada a uma crônica familiar. Lembraria também a ocorrência de aforismos, descrições, reflexões, apresentados sob forma poética e funcionando freqüentemente como verso. Alguns livros já antigos, como Os discípulos de Emaús, de Murilo Mendes, de 1944, ou ABC das catástrofes, de 1951, de Poemas em prosa, de 1955, ambos de Aníbal Machado, prenunciam esta tendência que se vai generalizando e corresponde a uma crise ou quem sabe supressão do conceito de gênero. Não vale a pena citar um grande número de obras recentes deste tipo, porque em geral não têm grande força. Citemos apenas, ainda aqui, um veterano que supera os nove, Murilo Mendes e seu recente livro Poliedro, de 1972, coleção admirável de pequenas descrições que lembra às vezes Le Parti-Pris des Choses, de Francis Ponge, e bem exprime o modo de ser que Murilo Mendes atribue a si mesmo: "visionário realista".

É natural que muitas produções dos jovens, rebeldes às tradições, às definições e por vezes à própria cultura, revelem essa confusão de gêneros que permite todas as liberdades. $\hat{E}$ o caso de um tipo de literatura violentamente anti-convencional, que parece feita com sucata de cultura, como, entre outros, o curioso Me segura que eu vou dar um troco, recentemente publicado por Wally Sailormoon, pseudônimo trocadilhesco, de acôrdo com a moda, de Wadi Salomão. Nele se cruzam o protesto, o desacato, o testemunho, o desabafo, o relato, - tudo numa linguagem baseada geralmente na associação livre e na enumeração caótica, formada de frases coloquiais, gíria "hippie", obscenidades, períodos truncados, elipses violentas, transições abruptas, resultando um movimento bastante vivo cuja matéria é a experiência pessoal do autor. Aqui, não podemos falar de memórias, nem de relato, nem de ficção, nem de poesia, nem mesmo de estilo. É a literatura anti-literária, traduzindo uma espécie de erupção inconformista.

Falar em inconformismo nos leva à presença da política na literatura brasileira dos últimos anos. O atual regime militar do Brasil é de natureza a despertar o protesto incessante dos artistas, escritores e intelectuais em geral, e seria impossível que isto não aparecesse nas obras criativas, por mais interessadas que estejam em experimentos de fatura. Por outro lado, este tipo de manifestação é extremamente dificultada pelo regime, que exerce um controle severo sobre os meios de comunicação. Controle total na televisão e no rádio, quase total nos jornais de maior circulação, muito grande no teatro e na canção; nos livros e nos periódicos de pouca circulação a repressão é mais branda, porque varia na razão direta do alcance dos meios de comunicação. 
Além disto, existe em escala nunca vista antes a repressão sobre os indivíduos; ela levou milhares de intelectuais à prisāo, à expatriação, à privação de cargos e funções; ela leva dezenas de milhares, cada dia e cada minuto, ao que se chamou no tempo do nazismo de "migração interior", isto é, a fuga para dentro de si mesmo, o silêncio, a auto-repressão. Este estado de coisas foi grave de 1964 a 1967, abrandou em 1968, mas no fim desse ano entrou numa fase que dura até hoje e pode sem exagero ser qualificada de terrivel.

É claro que isto afeta a atividade intelectual e limita as possibilidades de expressão. Mas é difícil dizer se influe na natureza e sobretudo na qualidade das obras criativas. Nada pode impedir que nalgum lugar algum escritor esteja produzindo obras que no futuro se revelarão as mais importantes de nosso tempo, apesar da repressão, da violência e das tensões interiores. $O$ que desejo aqui é apenas indicar alguns reflexos da situação no ânimo dos escritores e no temário das obras que estão sendo publicadas.

Há uma pequena produção de contos e romances que abordam a violência corrente com grande coragem; e penso que muitos outros são recusados pelos editores, que hesitam em arriscar a sua situação numa empresa que pode virar aventura perigosa. A este propósito eu gostaria de assinalar a atividade corajosa da Editora Civilização Brasileira, que, apesar de constantemente perseguida econômica e politicamente, faz o possível para manter uma linha inconformista de edições, tanto de livros originais quanto dos traduzidos.

É ela a editora de Antonio Calado, cujo romance Quarup, de 1967, é considerado típico da situação em que vivemos e descreve o movimento de cultura popular e a repressão no Nordeste do país nos primeiros momentos da chamada Revolução de 1964. O livro teve grande êxito e foi traduzido em várias línguas, inclusive inglês; mas acho melhor realizado outro do autor, 0 corajoso e significativo Bar Don Juan, de 1972, que narra as disposições rebeldes de um certo tipo de intelligentsia boêmia, sua participação na luta armada e seu esmagamento final.

É preciso lembrar ainda o veterano Erico Veríssimo, que publicou em 1971 o corajoso romance Incidente em Antares, onde insere uma espécie de fábula macabra, na qual os mortos voltam à vida para proferirem uma crítica contundente da situação, e em geral da ética dominante na sociedade burguesa.

Neste sentido, tem tido grande importância a canção popular, constantemente reprimida pelas autoridades, mas insistindo em retratar com sinceridade o atual estado de coisas. Através da linguagem figurada e da exploração sistemática da ambigüidade, tem sido possível a alguns compositores-poetas dizer muita coisa que encarna o protesto e manifesta a crítica, motivando freqüentemente a proibição de seus discos e espetáculos, o que tem acontecido sobretudo com o serenamente bravo Chico Buarque de Holanda. 
Estes artistas representam um lado da criação literária em fase de transformação rápida. A aliança entre a música e a palavra permite certa incorporação dos jogos de sonoridade e sentido das experiências de vanguarda, e sua incorporação quase insensível à sensibilidade popular. Chico Buarque se coloca numa posição mais lírica e sentimental, que lembra a de Vinicius de Moraes, poeta eminente transformado em autor de canções. Caetano Veloso manifesta afinidade com soluçōes da poesia concreta, cujo intelectualismo é curioso ver no universo deste artista que foi um dos principais figurantes do Tropicalismo.

O colorido movimento tropicalista ocorreu brevemente depois de 1965, sobretudo na canção e no teatro, como uma violenta explosão expressionista. O seu momento culminante talvez tenha sido, em 1966, a montagem da peça $O$ rei da vela, de Oswald de Andrade, publicada em 1937 mas nunca representada antes. Explorando arbitrariamente as virtualidades de um texto de vanguarda com rara capacidade inventiva, o Diretor José Celso Correa Martinez criou uma espécie de manifestação dionisíaca que sacudiu a opinião pública, influenciou a visão dos jovens e abriu caminho para formas agressivas de espetáculo, canção e mesmo poesia.

Num ensaio publicado em 1970 na revista francesa Temps Modernes, o crítico Roberto Schwarz estudou o Tropicalismo no contexto da situação política, como uma das muitas manifestações de irracionalidade que têm funcionado à maneira de revolta num país submetido à ditadura. Revolta que contunde os hábitos correntes, mas leva apenas ao nilismo. Segundo Schwarz, que mostra a sua semelhança com o movimento Pop, o Tropicalismo é fruto da coexistência de um conteúdo arcaico da cultura burguesa brasileira e das formas avançadas de expressão, com o intuito deliberado de criar situações absurdas. Podemos completar dizendo que neste caso ele abriu caminho para as atuais manifestações do que está em moda chamar de "contra-cultura", e que parece uma rebelião patética de impotência, quando encarada do ângulo político.

A referência a Oswald de Andrade nos faz pensar em como a situação literária presente está marcada pela renovação da influência dos grandes modernistas, como ele e Mário de Andrade. No ano de 1972 houve comemorações do $50^{\circ}$ aniversário da Semana de Arte Moderna, realizada em São Paulo em 1922 e considerada ponto de partida de uma revolução literária permanente, que ainda não cessou de abalar e transformar os gêneros e sua linguagem. Estas comemorações mostraram, de um lado, o que há de envelhecido e já arquivado; mas mostraram também como estão vivas e atuantes as partes essenciais daquela grande e alegre revolta. Mário de Andrade e Oswald de Andrade (que não são parentes apesar da coincidência dos nomes) nos aparecem hoje como figuras vivas e atuantes, fazendo parte do panorama literário.

Oswald de Andrade morreu em 1954 e sua obra era mal conhecida, apesar do rumor causado pela sua pessoa e pela sua lenda. Só agora a reedição de suas obras permitirá ao grande público um conhecimento 
direto e a formação de um juízo. Mas justamente a ignorância do público ajudou a formação de um mito muito útil para a renovação e implantação do espírito de vanguarda em nossos dias. Para os moços, Oswald é uma espécie de grande ponto de referência, uma fonte inspiradora de tudo que é novo, sobretudo graças à intensa campanha feita em prol do seu nome pelos poetas concretistas, conhecedores refinados de sua obra. Mas foi o citado espetáculo de José Celso Correa Martinez que o lançou junto ao grande público, transformando-o na bandeira de vanguarda que é hoje.

Mário de Andrade morto em 1945, conheceu em vida uma glória sólida e extensa, vendo a sua obra suficientemente difundida e comentada. Por um mecanismo quase normal da fama, estudado muito bem por Henri Peyre, entrou a seguir numa relativa área de sombra, de que talvez ainda custe para sair, junto à opinião mais dinâmica dos jovens renovadores. Há muitas afinidades entre ele e Oswald, e talvez o que este desejava fazer de mais sólido tenha sido feito por Mário no livro Macunaima, a obra mais importante do Modernismo brasileiro. Mas há também muitas diferenças, sendo que Mário poder ser considerado um revolucionário, enquanto Oswald seria sobretudo um terrorista das letras. Juntos, marcaram o Modernismo brasileiro, que só pode ser entendido se ambos forem igualmente considerados. Não tem maior sentido, senão polêmico, a dicotomia estabelecida há anos pelos então jovens concretistas, segundo a qual haveria uma opção quase irremediável a fazer entre Mário e Oswald. Meio século depois da Semana de Arte Moderna, nada mais expressivo da eminência de ambos do que o fato de sentirmos a sua presença e a das suas obras como um dos fatos mais importantes que estão acontecendo agora na literatura brasileira. 